\title{
Development of Imidazolium-type Anion-Exchange Membranes for Alkaline Fuel Cell Application
}

Jin Ran ${ }^{1}$, Liang Wu ${ }^{1}$, John R. Varcoe ${ }^{2}$, Ai Lien Ong ${ }^{2}$, Simon D. Poynton ${ }^{2}$, Tongwen $\mathrm{Xu}^{1 *}$

${ }^{1}$ CAS Key Laboratory of Soft Matter Chemistry, Lab of Functional Membranes,

School of Chemistry and Material Science, University of Science and Technology of China, Hefei 230026, P.R. China

${ }^{2}$ Department of Chemistry, The University of Surrey, Guildford, Surrey GU2 7XH, United Kingdom

${ }^{*}$ Corresponding author. Tel.: +86-551-360-1587. E-mail: twxu@ustc.edu.cn (T. W. Xu). 
Abstract: This study reports the development of imidazolium-type anion exchange membranes (Im-AEMs) based on the functionalization of bromomethylated poly(2,6-dimethyl-1,4-phenylene oxide) (BPPO) using 1-methylimdazole. Aromatic polymers bearing bromomethyl, instead of chloromethyl, functional groups were employed as base materials to avoid complicated chloromethylation which require toxic reagents. ${ }^{1} \mathrm{H}$ NMR and FT-IR spectroscopic data indicated the synthesis of a series of membranes with controlled ion-exchange capacities (achieved by varying the amount of 1-methylimdazole). Due to the conjugated structures of imidazolium cations, the novel Im-AEMs display enhanced short-term thermal and chemical stabilities compared with classical quaternary ammonium-type AEMs. In addition, the imidazolium salts exhibit excellent solubility in polar aprotic solvents, such as NMP and DMSO, which allowed the exploitation of a pre-functionalized strategy for the synthesis of the AEMs. As a consequence, the Im-AEMs displayed conductivities up to $>100 \mathrm{mS} \mathrm{cm}{ }^{-1}$ at $80^{\circ} \mathrm{C}$, which could be attributed to the establishment of a nano-scale phase-separated morphology as directed by the solvent casting process. A $\mathrm{H}_{2} / \mathrm{O}_{2}$ fuel cell test yielded a peak power density of $30 \mathrm{~mW} \mathrm{~cm}^{-2}$ at a current density of $76 \mathrm{~mA} \mathrm{~cm}$; ; this will be improved on development of a chemical compatible imidazolium-based alkaline ionomer for use as ionic polymer binder in the electrodes' catalyst layers.

Key words: imidazolium; bromomethylated poly(2,6-dimethyl-1,4-phenylene oxide); anion-exchange membranes; fuel cells

\section{Introduction}

There is increasing international interest in the development of alkaline polymer electrolyte fuel cells (APEFCs), containing alkaline anion exchange membranes (AAEMs), due to the perceived advantages over their acidic polymer electrolyte counterparts (Proton-Exchange Membrane Fuel Cells, PEMFCs). ${ }^{1-6}$ For example, the fuel oxidation and oxygen reduction reactions exhibit inherently faster kinetics in the high $\mathrm{pH}$ environments in APEFCs, thus allowing a wide range of non-precious-metal catalysts (e.g., nickel and manganese oxides) to be employed. Moreover, the direction of alkaline anion (e.g. hydroxide) transport opposes the direction, and therefore reduces, undesirable fuel crossover. ${ }^{7-11}$ AAEMs are a crucial component of APEFCs and therefore require considerable development. Unlike the proton exchange membranes (PEMs), such as the Nafion ${ }^{\circledR}$-series of perfluorinated sulfonic acid polymer electrolytes (developed by $\mathrm{Du}$ Pont) of excellent $\mathrm{H}^{+}$conductivities and chemical stabilities, that are used in PEMFCs, ${ }^{12,13}$ the AAEMs used in APEFC are poorer in alkaline anion conduction and chemical and thermal stability. Hence, a research priority is to develop AAEMs that possess high anion conductivities and excellent chemical and thermal stabilities as well as being low in cost.

To date, the most commonly studied AAEMs contain quaternary ammonium (QA) cationic groups and are prepared via post-functionalization of base polymer films. ${ }^{3,14-17}$ However, in order to introduce such QA groups, extremely volatile 
reagents, such as trimethylamine (TMA), are employed, resulting in an environmentally unfriendly synthetic process. The low alkali thermochemical stabilities of QA-type AAEMs limit their long-term durability of APEFCs. This poor stability in alkaline conditions derives from the strong nucleophilicity of the $\mathrm{OH}^{-}$ anions, which induces displacement ( $\mathrm{S}_{\mathrm{N} 2}$, or via ylide intermediates) and Hofmann elimination reactions (predominantly the latter when $ß$-hydrogens present). ${ }^{18-21}$

With the aim of obtaining AAEMs with enhanced stability, alternative cationic head-groups including guanidinium, ${ }^{22,23}$ stabilized phosphonium, ${ }^{24,25}$ and imidazolium, ${ }^{26-30}$ have been recently investigated. Zhang and co-workers reported a new class of AAEMs containing guanidinium head-groups, which maintained ionic conductivity even after immersion in aqueous $\mathrm{NaOH}\left(1 \mathrm{~mol} \mathrm{dm}^{-3}\right)$ for a week at room temperature; this suggested good alkaline stability. ${ }^{23} \mathrm{Yu}$ et al. prepared high-performance AAEMs using tris(2,4,6-trimethoxyphenyl)phosphine and chloromethylated polyfulones yielding the quaternary phosphonium analogue AAEMs. Again alkaline stability was suggested as there was no decrease of conductivity after immersing of the AAEMs in concentrates aqueous $\mathrm{NaOH}$ (10 mol $\mathrm{dm}^{-3}$ ) after $48 \mathrm{~h}$ at room temperature. ${ }^{25}$ However, these guanidinium and phosphonium-based AAEMs are high cost from the use of expensive functional reagents (pentamenthylguanidine and tris(2,4,6-trimethoxyphenyl)phosphine). With the aim of producing AAEMs with a balance between cost effectiveness and high performance, low-priced 1-methylimdazole was chosen as the functional reagent for the fabrication of imidazolium-type AAEMs (Im-AAEM).

The degradation of imidazolium cations in alkaline environments may be minimized due to the presence of steric hindrances and the П-conjugated structure of the five-member heterocyclic ring. In addition, it has been reported that Im-type AAEMs possess higher thermal stabilities compared to the conventional QA-type AAEMs. ${ }^{31,32}$ Im-type AAEMs may also possess different solubility properties compared to QA-AAEM analogues and may dissolve in common solvents (allowing both solution casting of the ionic polymers in the preparation process and the use of the anion-exchange polymer electrolytes as an alkaline ionomers to enhance the ionic contact in the catalyst layers of the fuel cell electrodes). QA groups are commonly introduced into the membranes via a post-functionalized method (i.e. the ionic functionality is introduced after the membranes are cast); this inhibits the formation of ion transport channels (for enhanced ionic conductivity) since there is no driving force for ion aggregation or phase separation during the functionalized process. ${ }^{33}$ In contrast, the imidazolium chemistry is more amenable to AAEM fabrication via a pre-functionalized strategy (i.e. the ionic polymers are cast), which favors the formation of ion clusters for efficient alkali-anion transport.

A number of groups have recently devoted their efforts to fabricating Im-AAEMs featuring aliphatic main chains via the polymerization of imidazolium pre-functionalized monomers. ${ }^{28,} 34$ However, the mechanical integrity of such aliphatic-chain polymers is likely to be compromised at the working temperatures of fuel cells due to the typically low glass-transition temperature of such polymers. ${ }^{35}$ To address the above, this study targets the preparation of Im-AAEMs via the reaction 
of 1-methylimidazole with bromomethylated poly(phenylene oxide) (BPPO); these resulting BPPO-Im AAEMs contain stiff aromatic polymer main chains. This reaction has been developed in our laboratory in order to avoid chloromethylation reactions that tend to require the use of toxic (often carcinogenic) reagents. This methodology allows the formation of bromomethyl groups via rapid and quantitative bromination of methyl groups attached to the benzene rings in the polymer. ${ }^{36,37}$ In addition, on account of the superior physicochemical properties of poly(2,6-dimethyl-1,4-phenylene oxide) (PPO) based membranes, the resultant Im-AAEMs display excellent thermal, mechanical and chemical stabilities as well as promising ionic conductivities. By adjustment of the 1-methylimidazole to bromomethyl group ratio, a series of Im-AAEMs with different IECs were obtained. From the practical application point of view, the Im-AAEMs were evaluated in a $\mathrm{H}_{2}$ fuel cell.

\section{Experimental}

\section{Materials}

Bromomethylated poly(phenylene oxide) (BPPO) was kindly provided by Tianwei Membrane Corporation Ltd. (Shandong, China). The commercial BPPO was purified by dissolving in NMP, precipitating in methanol, and drying at $40^{\circ} \mathrm{C}$. ${ }^{1} \mathrm{H}-\mathrm{NMR}$ indcates $57.8 \%$ bromobenzyl $\left(\phi-\mathrm{CH}_{2} \mathrm{Br}\right)$ and $42.2 \%$ aryl bromide $(\phi-\mathrm{Br})$ per repeat unit. 1-Methylimidazole (MIm) was purchased from Alfa Aesar (UK). Sodium chloride (AR grade), N-methyl-2-pyrrolidolone (NMP, AR grade), and sodium sulfate (AR grade) were purchased from Shanghai-Sinopham Chemical Reagent Co. Ltd (China). All these reagents and solvents were used as received without further purification. Deionized water (GRADE I OR II?) was used throughout.

\section{Preparation of the imidazolium alkaline anion-exchange membranes (Im-AAEM)}

The Im-AAEMs were prepared via the solution-casting method. Firstly, a homogeneous solution of BPPO $(15 \% \mathrm{~m} / \mathrm{v})$ was prepared using $\mathrm{N}$-methyl-2-pyrrolidolone (NMP) as the solvent. 1-Methylimidazole was added (controlled amount) and the resulting mixtures were stirred at $40^{\circ} \mathrm{C}$ overnight. The solutions of the ionic polymers were then cast onto clean glass plates and heated at $60^{\circ} \mathrm{C}$ for $24 \mathrm{~h}$ (solvent evaporation) and then $80^{\circ} \mathrm{C}$ for $24 \mathrm{~h}$ (evaporation of unreacted 1-methylimidazole). The resultant anion-exchange membranes ( $\mathrm{Br}^{-}$anion form) were peeled off the glass plates and soaked in aqueous $\mathrm{NaOH}\left(1 \mathrm{~mol} \mathrm{dm}^{-3}\right)$ solution at room temperature for $48 \mathrm{~h}$ (exchange of the $\mathrm{Br}^{-}$anions for the desired $\mathrm{OH}^{-}$anions). The Im-AAEMs synthesized were finally thoroughly washed with deionized water to remove residual (excess) $\mathrm{NaOH}$ prior to characterization and study.

\section{Characterizations of polymers}


${ }^{1} \mathrm{H}$ NMR spectra were recorded on a DMX 300 NMR spectrometer $\left({ }^{1} \mathrm{H}\right.$ resonance at $300 \mathrm{MHz}$ ). FT-IR spectra were recorded on thin membrane samples using a Vector 22 spectrometer (Bruker).

\section{Characterization of the physiochemical properties of the Im-AAEMs}

Water Uptake and Swelling Ratio A sample of membrane $(4 \mathrm{~cm}$ in length and $1 \mathrm{~cm}$ in width) was immersed in deionized water at a given temperature for $24 \mathrm{~h}$. After this hydration step, the sample was removed from the water, the surfaces wiped with tissue paper (to remove excess surface water) and the mass and length were quickly measured. The water uptake of membranes was calculated as follows:

$$
W u=\frac{W w e t-W d r y}{W d r y} \times 100 \%
$$

where $W w e t=$ the hydrated mass and $W d r y=$ the mass of the sample when dehydrated (recorded after the Im-AAEMs were dried by XXXX).

The linear expansion ratio (LER) was similarly calculated as:

$$
L E R=\frac{l w e t-l d r y}{l d r y} \times 100 \%
$$

where $l w e t=$ the hydrated length of the sample and ldry $=$ the length of the sample once dehydrated.

Ion Exchange Capacity (IEC) The IEC was measured using the Mohr method. Firstly, the membranes (in $\mathrm{Cl}^{-}$) were washed with deionized water and dried at $80^{\circ} \mathrm{C}$ under vacuum for $24 \mathrm{~h}$ before the masses were recorded. The membranes were then converted into the $\mathrm{SO}_{4}{ }^{2-}$ form by immersion in aqueous $\mathrm{Na}_{2} \mathrm{SO}_{4}\left(0.5 \mathrm{~mol} \mathrm{dm}{ }^{-3}\right)$ solution for $8 \mathrm{~h}$. The $\mathrm{Cl}^{-}$ions, released from the membranes, were then titrated with aqueous $\mathrm{AgNO}_{3}\left(0.1 \mathrm{~mol} \mathrm{dm}{ }^{-3}\right)$ aqueous solution using $\mathrm{K}_{2} \mathrm{CrO}_{4}$ as a colorimetric indicator. The IECs (expressed as $\mathrm{mmol} \mathrm{g}^{-1}$ ), were calculated from the amount of $\mathrm{AgNO}_{3}\left(1: 1 \mathrm{Ag}^{+}: \mathrm{Cl}^{-}\right.$reaction) consumed in the titration and the mass of the dry membrane.

Hydroxide Conductivity The measurement of the ionic conductivity of an AAEM was conducted in a similar manner to the measurement of the proton conductivities of PEMs using the four-point probe technique. The ionic conductivities were determined using an Autolab PGSTAT 30 (Eco Chemie, Netherland) in galvanostatic mode and with an a.c. current amplitude of $0.1 \mathrm{~mA}$ and a frequency range of $1 \mathrm{MHz}$ to $50 \mathrm{~Hz}$. Bode plots were used to determine the frequency region over which the magnitide of the impedance was constant; the ionic resistance was then obtained from the associated Nyquist plot. The AAEM being studied was set into a Teflon cell where it was in contact with 2 current collecting electrodes and 2 potential sensing electrodes (the distance between the potential sensing electrodes was $1 \mathrm{~cm}$ ). The cell was completely immersed in deionized water and the impedance spectrum was collected. This was done quickly to minimize the potential error caused by reaction of the hydroxide ions in the AAEM with dissolved carbon dioxide (resulting in the 
formation of carbonate/bicarbonate anions and reduced AAEM conductivity). The ionic conductivity was calculated according to the following equation: ${ }^{38}$

$$
\kappa=\frac{L}{R W d}
$$

where $R$ is the membrane resistance, $L$ is the distance between potential sensing electrodes, and $W$ and $d$ are the width (here $1 \mathrm{~cm}$ ) and thickness of the membrane respectively. All samples were equilibrated in water for $24 \mathrm{~h}$ prior to conductivity measurements. At the predetermined temperatures, the samples were equilibrated for at least $30 \mathrm{~min}$ before measurement: Values were recorded when constant ionic resistance were observed.

Thermal and Mechanical Analyses The short-term thermal stabilities of the samples were measured using a TGA Q5000 (TA Instruments) thermogravimetric analyzer under nitrogen atmosphere and with a heating rate of $10^{\circ} \mathrm{C} \min ^{-1}$. Tensile measurements of dry and fully humidified membranes were carried out using a Q800 dynamic mechanical analyzer (DMA, TA Instruments)) at a stretch rate of $0.5 \mathrm{~N}$ $\min ^{-1}$.

Atomic Force Microscopy (AFM) Tapping mode AFM observations were performed with a veeco diInnova SPM, using micro-fabricated cantilevers with a force constant of $20 \mathrm{~N} \mathrm{~m}^{-1}$.

Alkaline Stability Measurements The Im-AAEMs were immersed in aqueous $\mathrm{NaOH}\left(2 \mathrm{~mol} \mathrm{dm}^{-3}\right)$ solutions at $25^{\circ} \mathrm{CC}$ and $60^{\circ} \mathrm{C}$ for $28-192 \mathrm{~h}$. They were then thoroughly washed with deionized water (to remove the excess sodium hydroxide) and immersed in deionized water prior to the measurement of ionic conductivity (in the cell described above). To distinguish the conductivity of the AAEMs treated in alkaline solution for $24 \mathrm{~h}$ and the AAEMs treated for more than $24 \mathrm{~h}$, the former is designated $\sigma_{0}$, and the latter designated $\sigma_{\mathrm{t}}$. The $\sigma_{t} / \sigma_{0}$ ratios were recorded as a function of immersion time (in the alkaline solution).

\section{Fuel cell testing}

The performance of M-? was evaluated in a $\mathrm{H}_{2}$ fuel cell. The anode and cathode electrodes containing Surrey's first generation ionomer (SION1, quaternary ammonium-based) were prepared as follows. A catalyst ink was prepared by mixing the catalyst (20\%mass Pt/C, Johnson Matthey's HISPEC 3000 supplied by Alfa Aesar) and poly(vinylbenzyl chloride) binder using ethyl acetate as a solvent. The mixture was sonicated and then deposited on top of a microprous layer $\left(1 \mathrm{mg} \mathrm{cm}{ }^{-2}\right.$ and $20 \%$ mass PTFE as binder), that was located on one side of each of the wet-proofed (20\%mass PTFE) carbon paper gas diffusion electrode substrates, until the Pt loading of $0.4 \mathrm{mg} \mathrm{cm}$ (geometric) was achieved. To form the cross-linked alkaline anion-exchange interface polymer (SION1 alkaline ionomer), the treated electrodes were immersed in $N, N, N^{\prime}, N^{\prime}$-tetramethylhexane-1,6-diamine (99\%, Acros Oragnics) overnight before being thoroughly rinsed with Millipore water.

The membrane electrode assembly (MEA) was prepared by sandwiching the $\mathrm{OH}^{-}$ form of M-? between the anode and cathode with the alkaline ionomer treated catalyst 
layers facing the AAEM; no hot-pressing was used. The beginning-of-life performances of the MEAs (active geometric area of $5.3 \mathrm{~cm}^{2}$ ) was recorded using a Scribner $850 \mathrm{e}$ fuel cell test station (Scribner Associates Inc., USA) without back pressurisation of the gas supplies. Fuel cell test was conducted at $50^{\circ} \mathrm{C}$, with $\mathrm{H}_{2}$ and $\mathrm{O}_{2}$ gases with flow rates of $600 \mathrm{~cm}^{3} \mathrm{~min}^{-1}$ and controlled at relative humidity $\mathrm{RH}=$ $100 \%$.
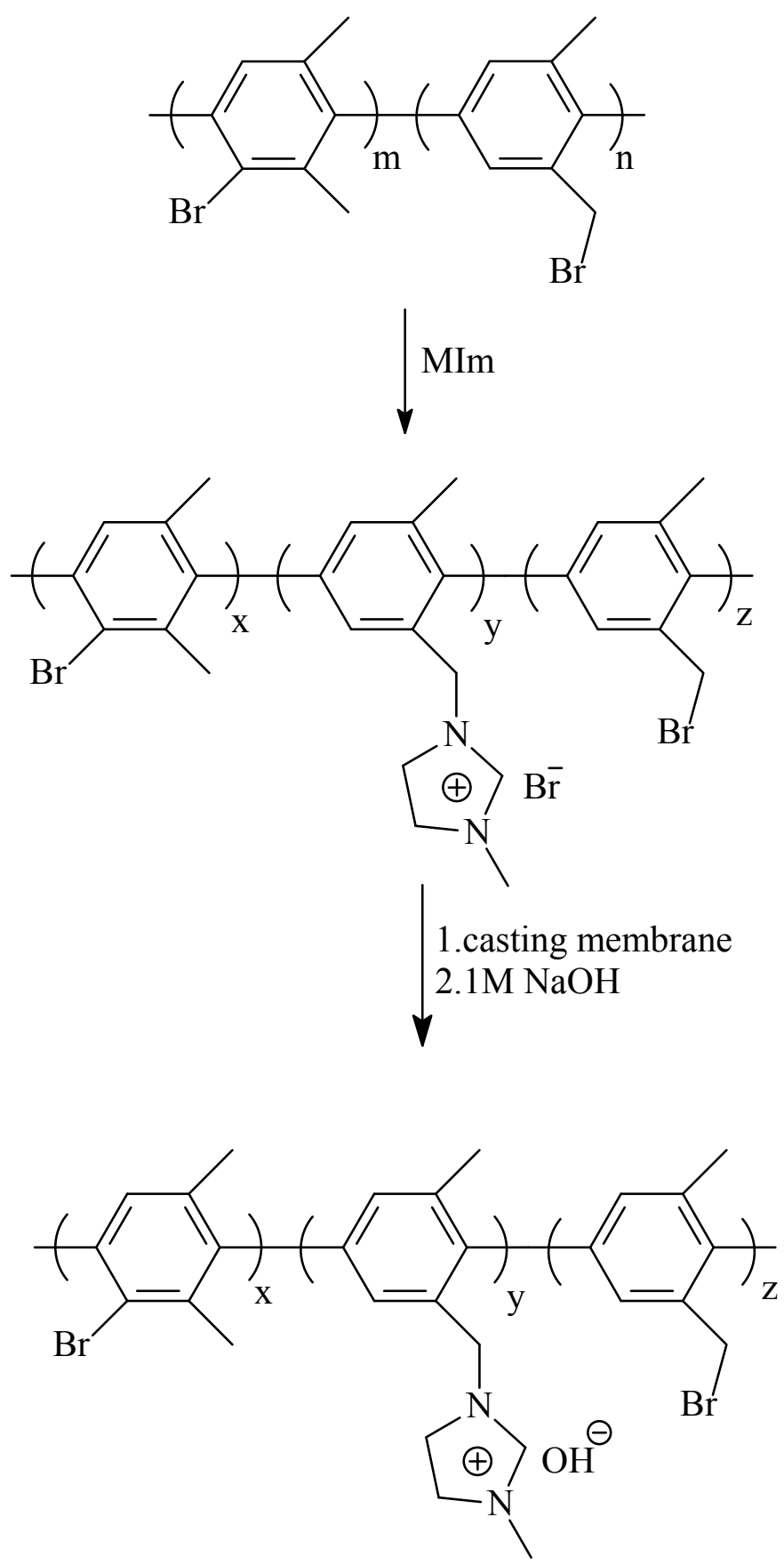

Fig. 1 Schematic of the preparation of bromomethylated poly(phenylene oxide) (BPPO)-based imidazolium alkaline anion-exchange membranes (Im-AAEM)

\section{Results and Discussion}




\section{Membrane preparation}

As depicted in Fig. 1, Im-type AEMs were prepared using BPPO as the base polymer. During the period of reaction, the viscosities of the polymer solutions increased gradually, which is a result of electrostatic repulsive force between the cations that formed (leading to the chain extension). After sufficient reaction times, the BPPO-type Im-AAEMs were obtained via solution casting of the imidazolium polymer solution. All the resultant membranes were flexible, transparent, and could be cut into any desired shape. Notably, the BPPO-Im ionic polymer electrolytes exhibit excellent solubility in DMSO, which allowed the easy characterization of the synthesized polymers using ${ }^{1} \mathrm{H}$ NMR spectroscopy (and $\mathrm{d}^{6}$-DMSO as NMR solvent).

Table 1 Composition of BPPO-Im Membranes

\begin{tabular}{cccc}
\hline $\begin{array}{c}\text { Sample } \\
\text { Designation }\end{array}$ & BPPO (g) used & $\begin{array}{c}\text { 1-methylimidazole } \\
(\boldsymbol{\mu L} \mathbf{L}\end{array}$ & $\begin{array}{c}\text { Feed molar ratio of } \\
\mathbf{M I m} / \mathbf{- C} \mathbf{H}_{\mathbf{2}} \mathbf{B r}\end{array}$ \\
\hline M-1 & 3.00 & 180 & $25.9 / 100$ \\
M-2 & 3.00 & 300 & $43.2 / 100$ \\
M-3 & 3.00 & 420 & $60.4 / 100$ \\
M-4 & 3.00 & 600 & $86.3 / 100$ \\
M-5 & 3.00 & 900 & $129.5 / 100$ \\
\hline
\end{tabular}

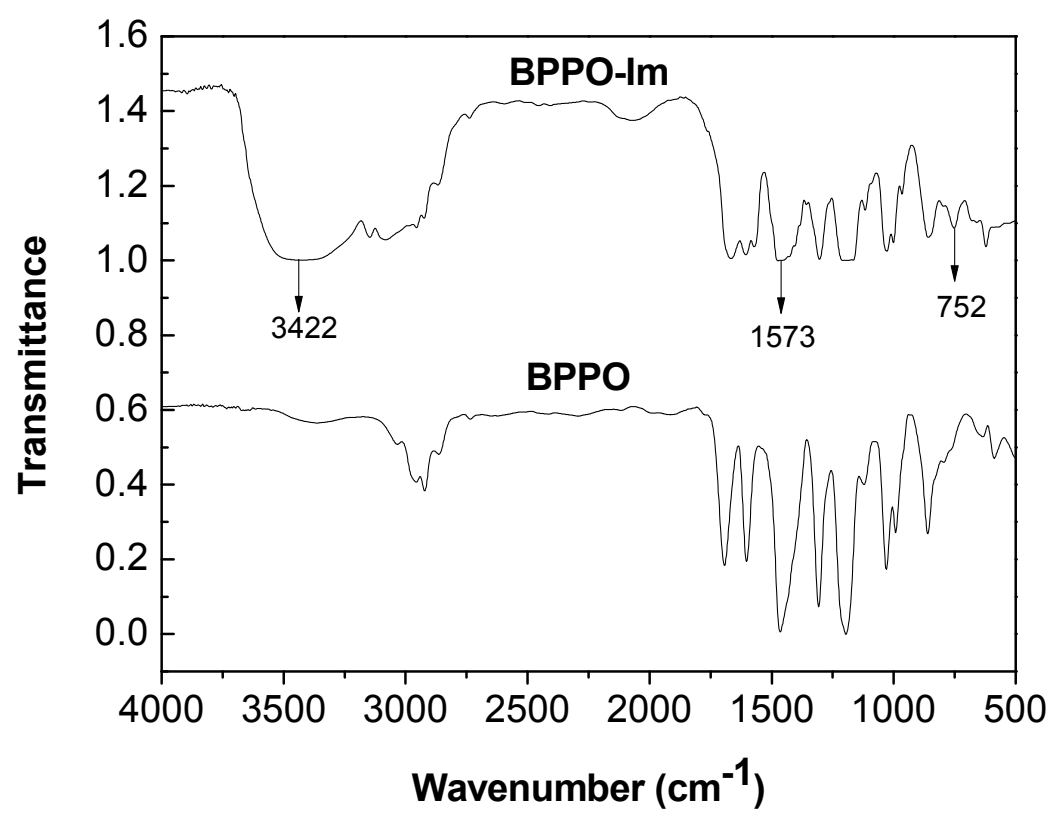

Fig. 2 FT-IR spectra of the BPPO base polymer and an exemplar product Im-AAEM (M-?)

Fig. 2 shows the FT-IR spectra of the base BPPO and M-? Im-AAEM. The sharp peak at $1573 \mathrm{~cm}^{-1}$ is attributed to the aliphatic stretching vibrations, and absorption at 
$752 \mathrm{~cm}^{-1}$ is assigned to the bending vibrations of imidazolium ring. Furthermore, a broad absorption peak at around $3422 \mathrm{~cm}^{-1}$ is observed in spectra of the Im-AAEMs but not in the BPPO spectrum; this absorption derives from the stretching vibrations of $\mathrm{O}-\mathrm{H}$ bonds due to the presence of water in the AAEMs. These results indicate the successful introduction of imidazolium functional groups into the membranes.

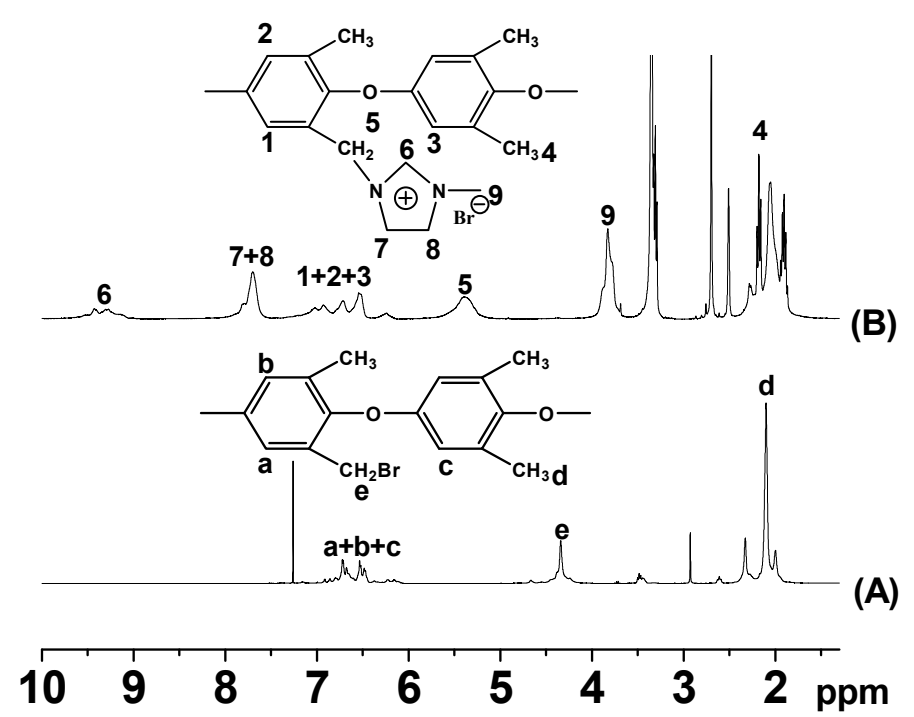

Fig. $3{ }^{1}$ H NMR spectra of BPPO (A) and M-? Im-AAEM (B)

Further confirmation of the successful synthesis of the Im-AAEM is based on ${ }^{1} \mathrm{H}$ NMR data (Fig. 3). For the base BPPO, the peaks at $\delta=6.4-6.5$ are attributable to the aromatic protons, while the sharp peak at $\delta=4.4$ corresponds to the methylene $\left(\mathrm{CH}_{2}\right)$ protons of the bromomethyl functional groups. After reaction with 1-methylimidazole, this methylene proton peak is located at lower chemical shifts as the result of deshielding. In addition, new peaks appear with the successful introduction of imidazolium cations: The $\delta=3.8$ peak is due to the methyl protons, and the $\delta=7.7$ and 9.2 peaks are due to the methylene protons of the imidazolium ring respectively.

Table 2 Ion exchange capacities, water uptakes, LERs, and hydroxide conductivities of the BPPO-based Im-AAEMs.

\begin{tabular}{ccccccccc}
\hline \multirow{2}{*}{ Sample } & \multicolumn{2}{c}{ IEC $\left(\mathbf{m m o l} \mathbf{g}^{-1}\right)$} & \multicolumn{2}{c}{ Water Uptake (\%) } & \multicolumn{2}{c}{ LER (\%) } & \multicolumn{2}{c}{$\begin{array}{c}\text { Conductivity } \\
\left(\mathbf{m S ~} \mathbf{~ m}^{-1}\right)\end{array}$} \\
\cline { 2 - 9 } & theoretical & experimental & $\mathbf{2 0}^{\circ} \mathbf{C}$ & $\mathbf{6 0}^{\circ} \mathbf{C}$ & $\mathbf{2 0}^{\circ} \mathbf{C}$ & $\mathbf{6 0}^{\circ} \mathbf{C}$ & $\mathbf{2 0}^{\circ} \mathbf{C}$ & $\mathbf{6 0}^{\circ} \mathbf{C}$ \\
\hline M-1 & 0.71 & 1.14 & 6.1 & 8.1 & 1.3 & 1.3 & 6 & 20 \\
M-2 & 1.14 & 1.51 & 11.1 & 13.8 & 2.6 & 2.6 & 9 & 26 \\
M-3 & 1.54 & 1.76 & 28.2 & 29.3 & 5.1 & 5.1 & 14 & 62 \\
M-4 & 2.08 & 2.21 & 58.2 & 62.7 & 10.0 & 15.0 & 24 & 66 \\
M-5 & 2.35 & 2.40 & 84 & 171 & 17.5 & 42.5 & 32 & 70 \\
\hline
\end{tabular}




\section{Hydroxide conductivity}

The hydroxide conductivity is a crucial AAEM property in relation to its application in fuel cells. As shown in table 2, the hydroxide conductivity of the Im-AAEMs increases with IEC due to the higher concentration of charge carriers and the volume fraction of water. The Im-AAEMs show high hydroxide conductivities especially M-5 which showed a hydroxide conductivity $32 \mathrm{mS} \mathrm{cm}^{-1}$ at room temperature; these excellent conductivities derive from the pre-functionalize strategy that directed the formation of ionic clusters during the solution casting process.
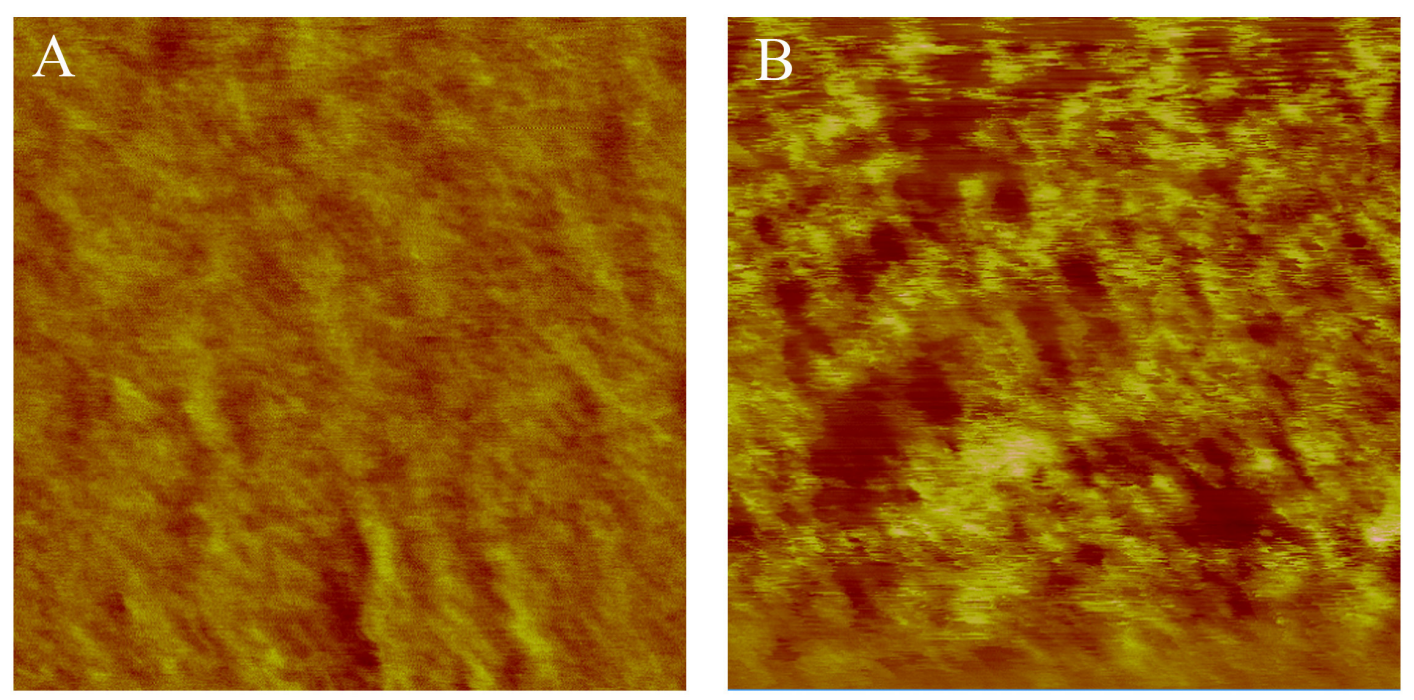

Fig. 4 AFM tapping phase images for select BPPO-type Im-AAEMs: (A) M-3, and (B) M-4. Scan boxes are $500 \mathrm{~nm} \times 500 \mathrm{~nm}$.

The phase images of the AAEMs recorded using tapping mode AFM under ambient conditions provides evidence in support of the above (Fig. 4); the dark regions correspond to the "soft" hydrophilic imidazolium ionic clusters and the bright domains correspond to the hard structures of the hydrophobic aromatic polymer backbones. Differences in the size of the ionic domains and the degree of phase separation are clear when comparing the phase images of M-3 and M-4. As the concentration of ionic groups increase, the hydrophilic regions become more inter-connected yielding superior ion conducting channels. These visible differences in morphology also provide an explanation of the sharp increase in conductivity and water uptake from M-3 to M-4 (table 2). 


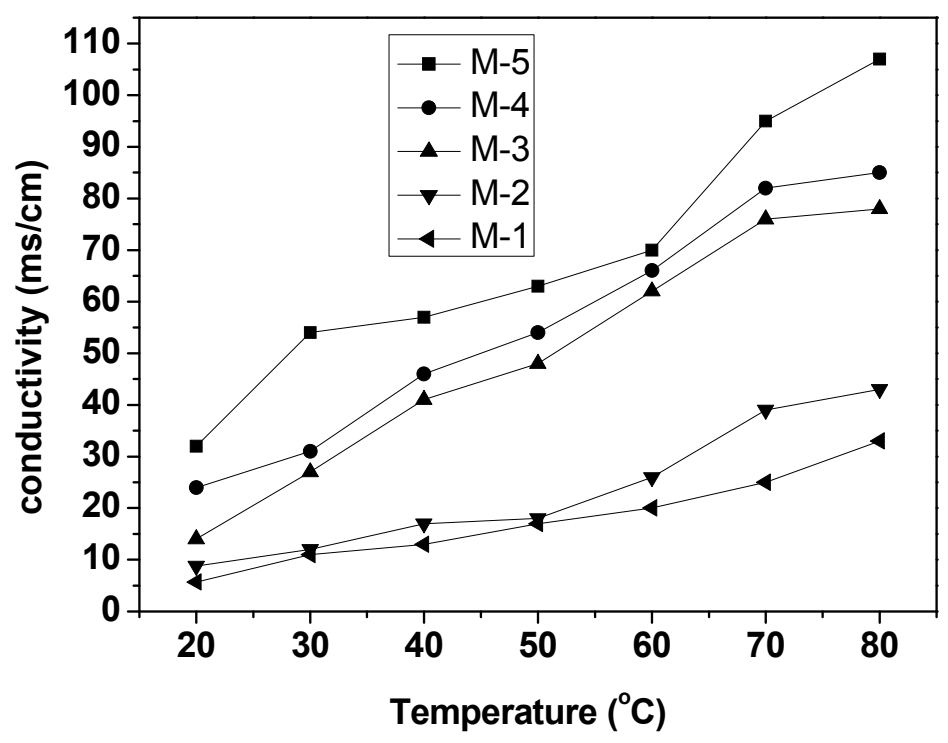

Fig. 5 The temperature dependence of the ionic conductivity of the $\mathrm{OH}^{-}$-form Im-AAEMs.

In relation to fuel cell performance, hydroxide conductivities are required (Fig. 5). As expected, the hydroxide conductivities are temperature dependent. For example, the conductivity of M-1 jumps from $5.7 \mathrm{mS} \mathrm{cm}^{-1}$ to $33 \mathrm{mS} \mathrm{cm}^{-1}$ when the temperature increased from $20^{\circ} \mathrm{C}$ to $80^{\circ} \mathrm{C}$. This trend can be explained for two reasons: (1) The polymeric main chains will increase in flexibility at elevated temperatures (providing a larger free volume in favor of enhanced ion transport); ${ }^{30}$ (2) Faster diffusion and thermal motion of hydroxide ions promote ion conduction at elevated temperatures (overcoming the activation energy for ion transport). ${ }^{39,40}$ Of particular note, M-5 exhibited ionic conductivities above $100 \mathrm{mS} \mathrm{cm}^{-1}$ at $80^{\circ} \mathrm{C}$ : This shows that the alkali anion conductivities of AAEMs can approach the magnitude of $\mathrm{H}^{+}$conduction in PEMs.

\section{Chemical and thermal stability}

Chemical stability a major concern for polymer electrolyte membranes applied in APEFCs due to the presence of highly alkaline environments (the nucleophilic $\mathrm{OH}^{-}$ attack the cationic head-groups and consequently reduce the concentration of ion exchange groups). To investigate the tolerance of the Im-AAEMs to alkaline environments, the change in conductivity of M-5 was monitored with immersion time in aqueous $\mathrm{NaOH}\left(2 \mathrm{~mol} \mathrm{dm}^{-3}\right)$ solutions at both $25^{\circ} \mathrm{C}$ and $60^{\circ} \mathrm{C}$ (Fig. 6). The same trend for was observed for both temperatures where the conductivity initially decreased and then stabilized over longer immersion times. For M-5, a drop of only $2 \%$ was observed within $28 \mathrm{~h}$ at $25^{\circ} \mathrm{C}$, whilst the final hydroxide conductivities reduced to $75 \%$ of beginning-of-test values at both $25^{\circ} \mathrm{C}$ and $60^{\circ} \mathrm{C}$. Visually, the 
initial yellow color changed to deep yellow with immersion time; this suggests the occurrence of some form of degradation.

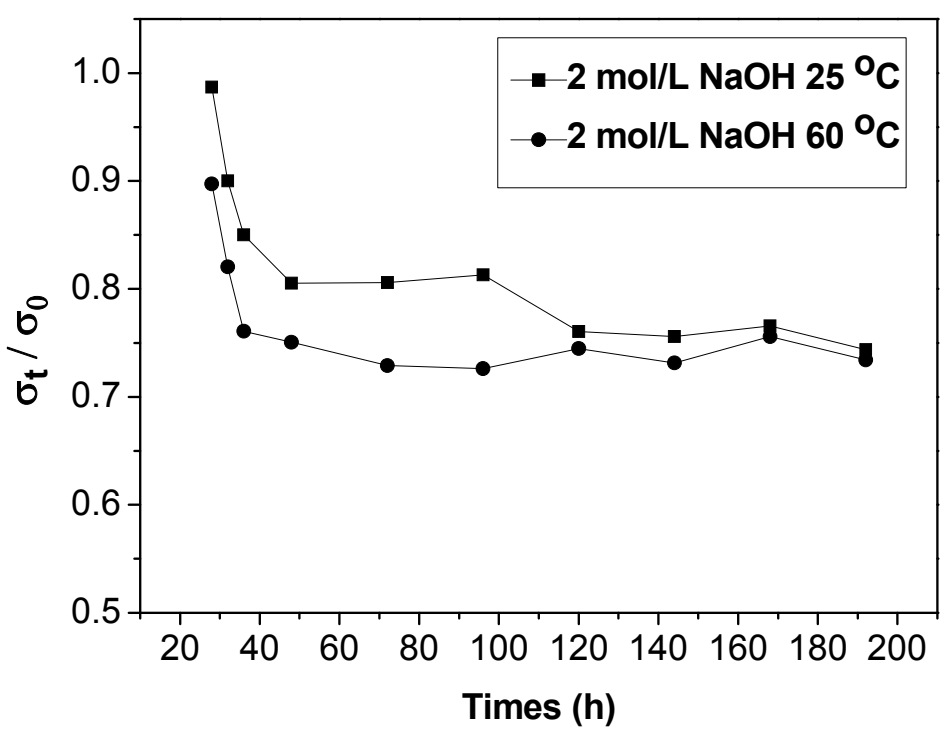

Fig. 6 The use of ionic conductivities to monitor the alkaline stability of Im-AAEM

M-5: The ratio of conductivity at time $t v s$. the beginning of test conductivity was monitored as a function of immersing time in aqueous $\mathrm{NaOH}\left(2 \mathrm{~mol} \mathrm{dm}^{-3}\right)$ solution at both $25^{\circ} \mathrm{C}$ and $60^{\circ} \mathrm{C}$.

The prior literature suggests that imidazolium moieties are as chemically stable (more more stable) than quaternary ammonium head-groups due to the presence of the five-membered heterocyclic ring \{REFS NEEDED\}. However, the alkaline durability of the BPPO-based Im-AAEMS, while acceptable, is not as high as for styrene-based imidaolium systems (reportedly stable in $\mathrm{NaOH}\left(2 \mathrm{~mol} \mathrm{dm}^{-3}\right)$ for $120 \mathrm{~h}$ at $60^{\circ} \mathrm{C}$ ). ${ }^{28} \mathrm{~A}$ plausible explanation is that the ether bond in the polymer main chains is not stable in concentrated alkaline solutions, an instability that is exasperated by the low compactness of the methyl groups of the polymers main chains (allows more hydroxide ions to penetrating into membrane network). Hence, further research into intrinsically more stable bromomethylated aromatic polymers is under the way with the aim of targeting Im-type AAEMs with enhanced alkali stability.

To complement the above medium-term assessment of chemical stability, thermal analyses were conducted to probe the short term thermal properties of the AAEMs (Fig. 7). The TGA curves of the base BPPO and M-? (in $\mathrm{OH}^{-}$form?) Im-AAEM were recorded under $\mathrm{N}_{2}$ atmosphere in the range 30 to $800^{\circ} \mathrm{C}$. Two primary regions of mass loss were clearly observed in the TGA curve for BPPO. The first weight loss commences at $c a .230^{\circ} \mathrm{C}$ and is attributed to the elimination of bromine atoms. The second mass loss commences at $c a .380^{\circ} \mathrm{C}$ and is accredited to the decomposition of the aromatic main chains. In contrast, M-? shows an additional 3\% mass loss at lower temperatures due to the loss of water bound to the imidazolium groups. Additionally, the decomposition of imidazolium cations initiates at $c a .170^{\circ} \mathrm{C}$, which is higher than 
the typical degradation on-set temperatures of $\mathrm{XXX}^{\circ} \mathrm{C}$ for quaternary ammonium cationic head-groups. ${ }^{41}$ Hence, over short-terms, imidazolium head-groups appear more stable than QA-type head-groups.

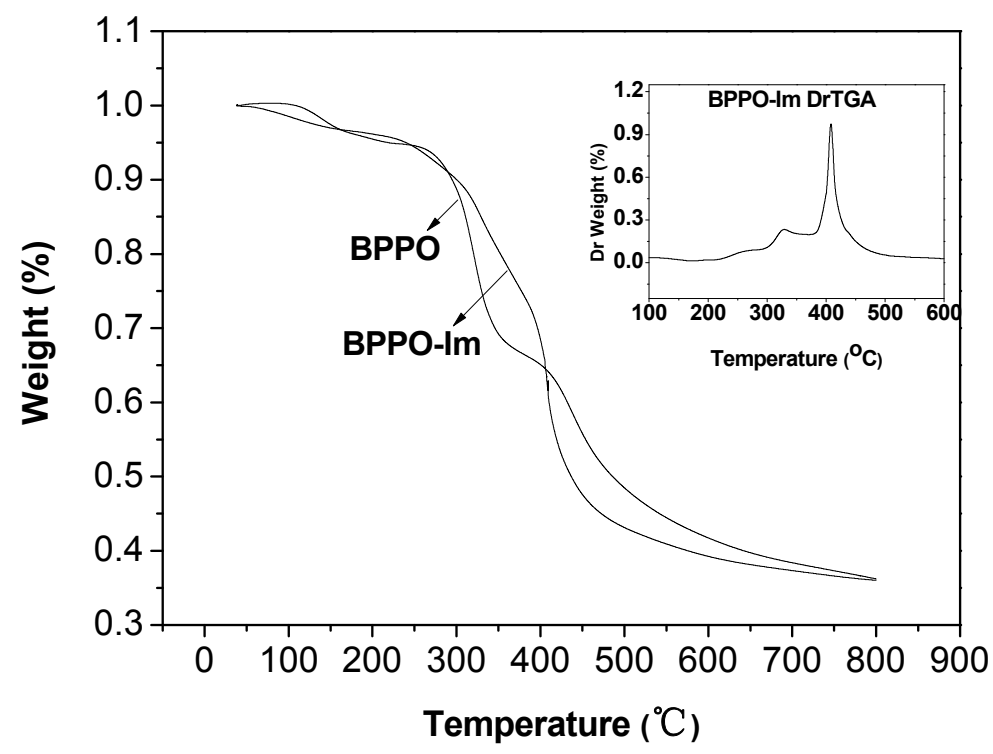

Fig. 7 TGA thermograms of BPPO and $\mathrm{M}-$ ? (in $\mathrm{OH}^{-}$form?) recorded using a $10^{\circ} \mathrm{C}$ $\min ^{-1}$ heating rate.

\section{Mechanical properties of membranes}

AAEMs must have enough mechanical strength and durability for, and during, application in fuel cells. Table 3 shows the mechanical properties of the synthesized Im-AAEMs with a range of IECs (for both the dry and wet states). The dry AAEMS displayed tensile strengths and elongations to break of $15.7-35.9 \mathrm{MPa}$ and $5.7-9.0 \%$ respectively. As presented in Fig. 8(A), a general trend of decreasing tensile strength with increasing IEC was observed (resulting from the increasing incorporation of ionic groups into the initially tight polymer chain network). The properties of the hydrated membranes are important since ion exchange membranes usually operate in their hydrated states. To study the mechanical properties of fully hydrated membranes, the Im-AAEMs were immersed in deionized water prior to testing. It is well known that water molecules disrupt the closely packed polymer chains resulting in the decline of the mechanical properties of the membranes. Due to the experimental errors involved, the decreased in tensile strength was too small to be detected with confidence, apart from M-5. Only for M-5 (with the highest water uptake of $84 \%$ mass) could the lowering of tensile strength and raising of the elongation to break be obviously observed on hydration (Fig. 8(B)). Despite this, the Im-AAEMs with the different IECs retained adequate tensile strengths when hydrated. hence fulfilling the mechanical strength demands when operated in fuel cells. 
Table 3 The key mechanical properties of the Im-AAEMs in the dry and wet states.

\begin{tabular}{ccccccc}
\hline \multirow{2}{*}{ Sample } & \multicolumn{2}{c}{ Tensile Strength (MPa) } & \multicolumn{2}{c}{ Young's modulus (GPa) } & \multicolumn{2}{c}{ Elongation at break (\%) } \\
\cline { 2 - 7 } & dry & wet & dry & wet & dry & wet \\
\hline M-1 & 35.9 & 28.9 & 2.2 & 0.9 & 5.7 & 7.2 \\
M-2 & 41.1 & 53.1 & 2.1 & 2.0 & 8.4 & 9.4 \\
M-3 & 25.7 & 31.2 & 0.9 & 1.2 & 6.7 & 6.5 \\
M-4 & 18.3 & 21.7 & 0.6 & 0.8 & 6.1 & 7.2 \\
M-5 & 15.7 & 11.5 & 0.4 & 0.2 & 9.0 & 44.1 \\
\hline
\end{tabular}
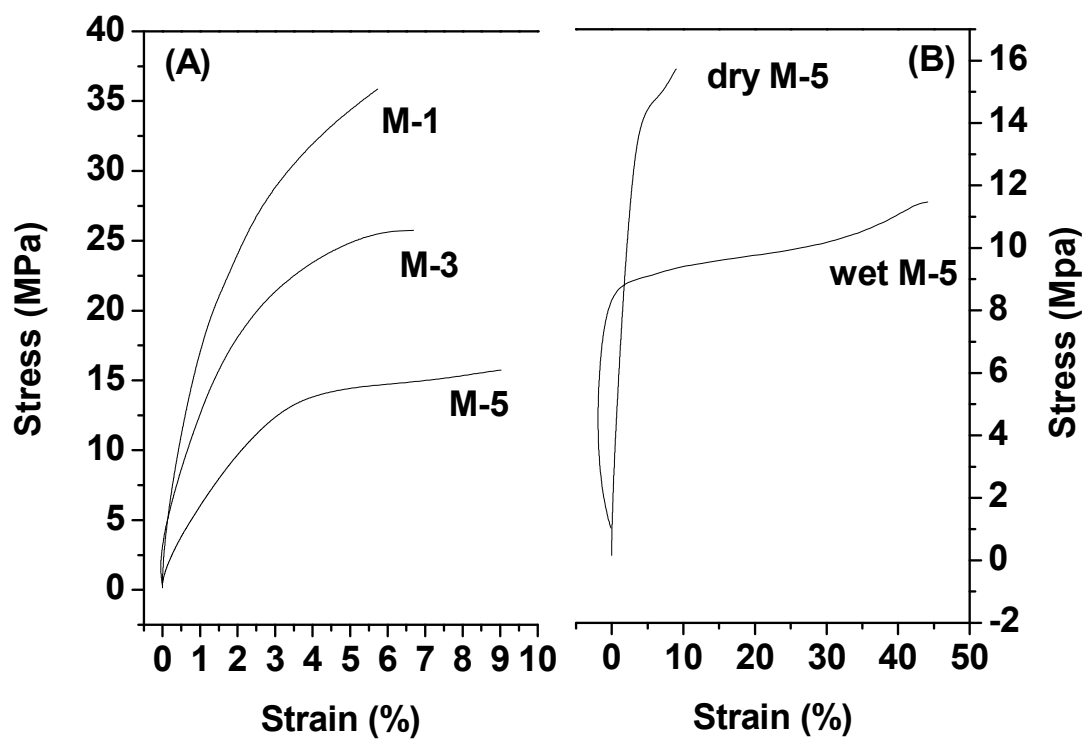

Fig. 8 (A) The stress-strain curves for select BPPO-type Im-AAEMs (in the XXX? state) and (B) the stress-strain curves for M-5 in both the dry and wet states.

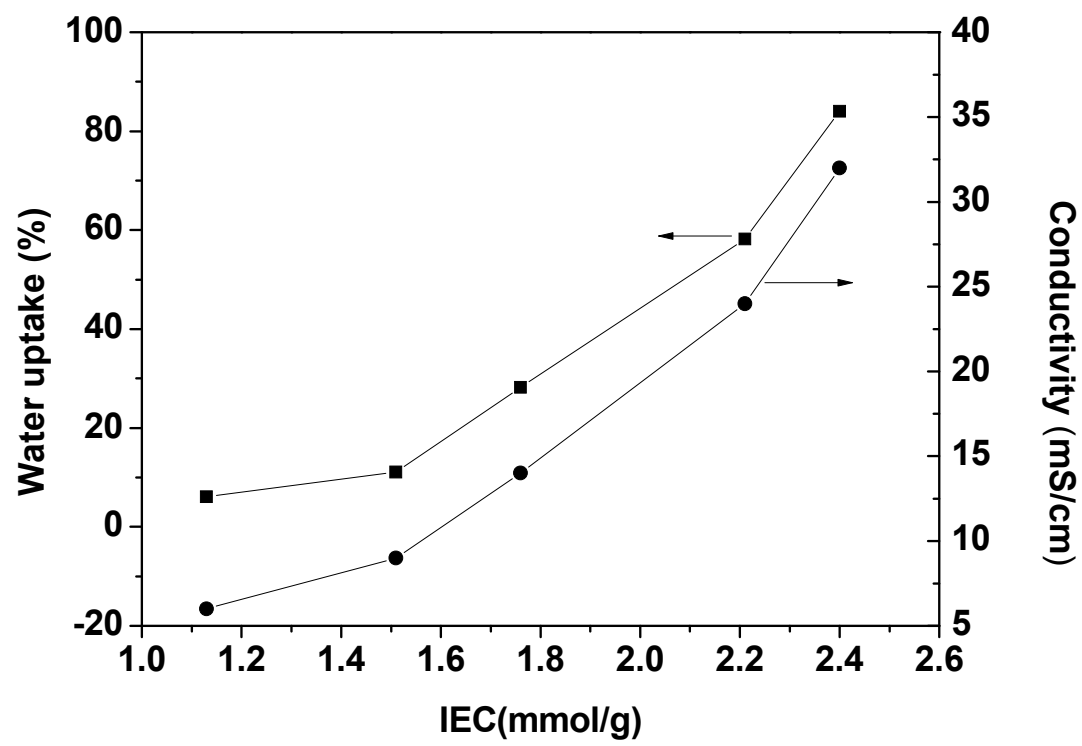

Fig. 9 The variation of water uptake and hydroxide conductivities with IEC. 


\section{Ion-exchange capacities (IEC), water uptakes (gravimmetric) and linear expansion ratios (LER)}

The IECs is a key characterization property of ion-exchange membranes and plays a key role in determining the water uptakes and conductivities. In principle, the IEC of an ion-exchange membrane should be as high as possible to provide maximized ionic conductivities (as long as the water uptakes and physical swelling is not excessive). In this class of AAEM, tunable IECs were achieved via adjusting the amount of 1-methylimidazole added during the synthesis process. Moreover, water uptake and linear expansion ratio, LER, (both often dictated by the IEC) also represent key parameters for evaluating ion-exchange membranes. However, excess water adsorption risks reducing dimensional and mechanical stability of the membranes. As shown in Fig. 9, both water uptakes and ionic conductivities increase with increasing IECs. Considering the overall balance of properties, M-5 is a promising candidate for fuel cell evaluation.

\section{Fuel cell testing}

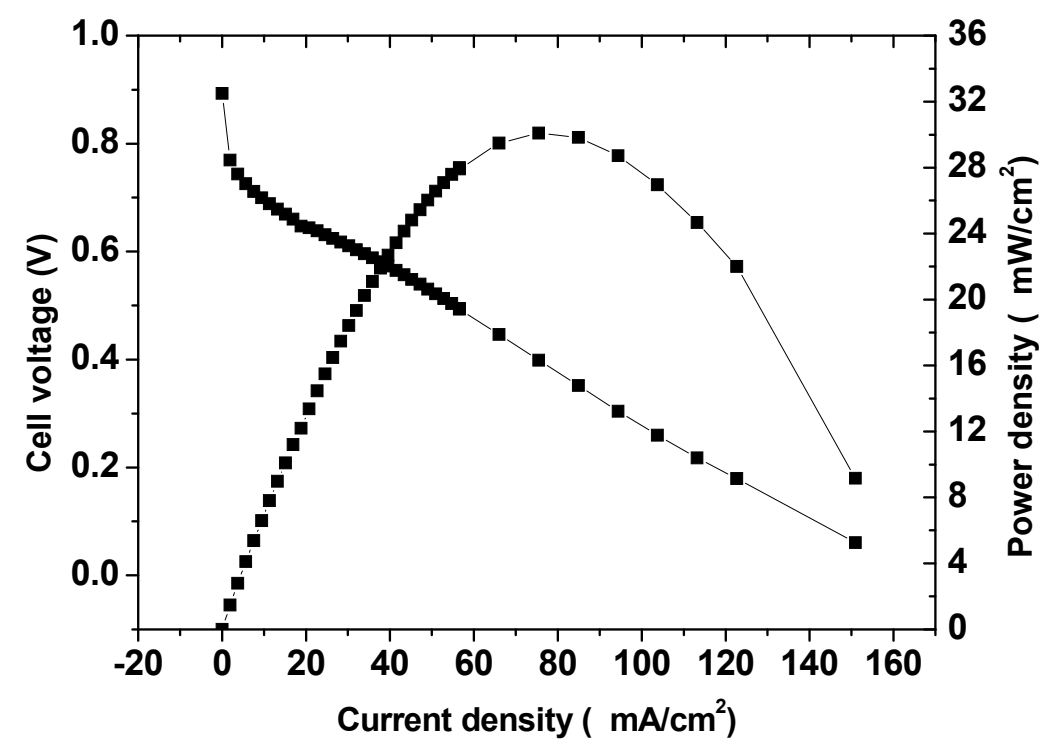

Fig. 10 Beginning-of-life polarization and power density curves at $50^{\circ} \mathrm{C}$ for an exemplar $\mathrm{H}_{2} / \mathrm{O}_{2}$ fuel cell containing M-5. The gas flows were fully hydrated with no back pressurisation.

The performances of a membrane electrode assemblies (MEAs) containing M-5 is presented in Fig. 10. The open circuit voltage (OCV) of the single cell was $0.89 \mathrm{~V}$ and a peak power density of $30 \mathrm{~mW} \mathrm{~cm}^{-2}$ (geometric) was obtained at a current density of $76 \mathrm{~mA} \mathrm{~cm}{ }^{-2}$ (geometric). This performance does not do justice to the high ex-situ conductivities recorded for M-5. Besides the AAEM's properties, the cell behavior is also affected by the activity of catalysts, the performance of the ionomer in the electrodes' catalyst layers (allows ion transport in these catalyst layers), and the MEA 
fabrication procedure (optimized flow dynamics). The alkaline ionomer used for these tests is quaternary ammonium based and so not expected to be chemically compatible with the head-group chemistry of the AAEM. Consequently, further research is being directed into optimizing these elements and in the production of a suitable imidazolium-based alkaline ionomer.

\section{Conclusions}

Novel imidazolium-type AAEMs (Im-AAEM) based on bromomethylated poly(phenylene oxide) (BPPO) polymer chains have been developed. The AAEMs were prepared via solution casting of NMP solutions of the anion-exchange polymer electrolyte material (to direct formation of a phase segregated morphology (ionic channel formation). By tuning the molar ratio of 1-methylimidazole to $\mathrm{CH}_{2} \mathrm{Br}$ groups in the starting polymer, a series of Im-AAEMs with different IECs ranging from 1.1 to $2.4 \mathrm{mmol} \mathrm{g}^{-1}$ were successfully prepared. Due to the phase segregated morphology, the Im-AAEMs display favorable hydroxide conductivities $\left(>100 \mathrm{mS} \mathrm{cm}^{-1}\right.$ at $80^{\circ} \mathrm{C}$ for the Im-AAEM with the highest ion-exchange capacity). In addition, the Im-AAEMs yielded good chemical and thermal stabilities. The results obtained suggest that the BPPO-based Im-AAEMs can claim convenient fabrication and high hydroxide conductivities. A single cell alkaline polymer electrolyte fuel cell employing an Im-AAEM yielded a beginning-of-life peak power density of $30 \mathrm{~mW}$

$\mathrm{cm}^{-2}$ at $50^{\circ} \mathrm{C}$. To fully demonstrate the promise of Im-based AAEMs in such fuel cells, a suitable imidazolium alkaline ionomer (to impart chemically compatible ionic conductivity to the catalyst layers of the electrodes) needs to be developed; this is the basis of on-going research.

\section{Acknowledgements}

We thank the financial supports from the National Basic Research Program of China (No. 2012CB932802,), the National Natural Science Foundation of China (nos. 21106140, 21025626, 20974106), and the Programs of Anhui Province for Science and Technology (No.11010202157). The University of Surrey researchers were supported by the UK's Engineering and Physical Sciences Research Council (grants $\mathrm{EP} / \mathrm{I004882/1}$ and EP/H025340/1).

\section{References}

1. R. Zeng, R. C. T. Slade, J. R. Varcoe, Electrochim. Acta, 2010, 56, 607-619.

2. Y. S. Li, T. S. Zhao and Z. X. Liang, J Power Sources, 2009, 187, 387-392.

3. L. A. Adams, S. D. Poynton, C. Tamain, R. T. C. Slade and J. R. Varcoe ChemSusChem, 2008, 1 79-81..

4. J. R. Varcoe and R. C. T. Slade, Fuel Cells, 2005, 5, 187-200.

5. R. Zeng, J. Handsel, S.D. Poynton, A.J. Roberts, R.C.T. Slade, H. Herman, D.C. Apperley, J.R. Varcoe, Energy and Environmental Science, 2011, 4 4925-4928.

6. Y. Chun-Chen, J Membrane Sci, 2007, 288, 51-60.

7. G. Erich, J Power Sources, 1996, 61, 99-104.

8. J. Fang and P. K. Shen, J Membrane Sci, 2006, 285, 317-322. 
9. K. Matsumoto, T. Fujigaya, H. Yanagi and N. Nakashima, Advanced Functional Materials, 2011, 21, 1089-1094.

10. N. J. Robertson, H. A. Kostalik, T. J. Clark, P. F. Mutolo, H. c. D. Abruña and G. W. Coates, J Am Chem Soc, 2010, 132, 3400-3404.

11. T. J. Clark, N. J. Robertson, H. A. Kostalik Iv, E. B. Lobkovsky, P. F. Mutolo, H. c. D. Abruña and G. W. Coates, J Am Chem Soc, 2009, 131, 12888-12889.

12. K. A. Mauritz and R. B. Moore, Chemical Reviews, 2004, 104, 4535-4586.

13. K. K.D, J Membrane Sci, 2001, 185, 29-39.

14. G. Wang, Y. Weng, D. Chu, D. Xie and R. Chen, J Membrane Sci, 2009, 326, 4-8.

15. G. Wang, Y. Weng, D. Chu, R. Chen and D. Xie, J Membrane Sci, 2009, 332, 63-68.

16. M. R. Hibbs, C. H. Fujimoto and C. J. Cornelius, Macromolecules, 2009, 42, 8316-8321.

17. J. R. Varcoe, R. C. T. Slade, E. Lam How Yee, S. D. Poynton, D. J. Driscoll, D. C. Apperley, Chem. Mater., 2007, 19, 2686-2693.

18. Y. Ye and Y. A. Elabd, Macromolecules, 2011, 44, 8494-8503.

19. S. Chempath, B. R. Einsla, L. R. Pratt, C. S. Macomber, J. M. Boncella, J. A. Rau and B. S. Pivovar, The Journal of Physical Chemistry C, 2008, 112, 3179-3182.

20. M. Tomoi, K. Yamaguchi, R. Ando, Y. Kantake, Y. Aosaki and H. Kubota, J Appl Polym Sci, 1997, 64, 1161-1167.

21. M. Mąkosza and A. A. Chesnokov, Tetrahedron, 2002, 58, 7295-7301.

22. J. Wang, S. Li and S. Zhang, Macromolecules, 2010, 43, 3890-3896.

23. Q. Zhang, S. Li and S. Zhang, Chem Commun, 2010, 46.

24. S. Gu, R. Cai and Y. Yan, Chem Commun, 2011, 47.

25. S. Gu, R. Cai, T. Luo, Z. Chen, M. Sun, Y. Liu, G. He and Y. Yan, Angewandte Chemie International Edition, 2009, 48, 6499-6502.

26. B. Lin, L. Qiu, B. Qiu, Y. Peng and F. Yan, Macromolecules, 2011, 44, 9642-9649.

27. F. Zhang, H. Zhang and C. Qu, journal of materials chemistry, 2011, 21.

28. W. Li, J. Fang, M. Lv, C. Chen, X. Chi, Y. Yang and Y. Zhang, journal of materials chemistry, 2011, 21.

29. O. D. Thomas, K. J. W. Y. Soo, T. J. Peckham, M. P. Kulkarni and S. Holdcroft, Polym Chem-Uk, 2011, 2.

30. B. Lin, L. Qiu, J. Lu and F. Yan, Chemistry of materials, 2010, 22, 6718-6725.

31. X. Kong, K. Wadhwa, J. G. Verkade and K. Schmidt-Rohr, Macromolecules, 2009, 42, 1659-1664.

32. A. D. Bishop Jr and J. L. Bear, Thermochimica Acta, 1972, 3, 399-409.

33. M. R. Hibbs, M. A. Hickner, T. M. Alam, S. K. Mclntyre, C. H. Fujimoto and C. J. Cornelius, Chemistry of materials, 2008, 20, 2566-2573.

34. M. Guo, J. Fang, H. Xu, W. Li, X. Lu, C. Lan and K. Li, J Membrane Sci, 2010, 362, 97-104.

35. R. Borup, J. Meyers, B. Pivovar, Y. S. Kim, R. Mukundan, N. Garland, D. Myers, M. Wilson, F. Garzon, D. Wood, P. Zelenay, K. More, K. Stroh, T. Zawodzinski, 
J. Boncella, J. E. McGrath, M. Inaba, K. Miyatake, M. Hori, K. Ota, Z. Ogumi, S. Miyata, A. Nishikata, Z. Siroma, Y. Uchimoto, K. Yasuda, K.-i. Kimijima and N. Iwashita, Chemical Reviews, 2007, 107, 3904-3951.

36. X. Tongwen and Y. Weihua, J Membrane Sci, 2001, 190, 159-166.

37. X. Tongwen and F. F. Zha, J Membrane Sci, 2002, 199, 203-210.

38. Y. Sone, P. Ekdunge and D. Simonsson, Journal of The Electrochemical Society, 1996, 143, 1254-1259.

39. D. S. Kim, G. P. Robertson and M. D. Guiver, Macromolecules, 2008, 41, 2126-2134.

40. D. S. Kim, G. P. Robertson, Y. S. Kim and M. D. Guiver, Macromolecules, 2009, 42, 957-963.

41. C. H. Lee, H. B. Park, Y. M. Lee and R. D. Lee, Ind Eng Chem Res, 2005, 44, 7617-7626. 